\title{
Factors Associated with the Lack of Adjuvant Chemotherapy Following Curative Surgery for Stage II and III Colon Cancer: A Korean National Cohort Study
}

\author{
GYE SUNG HA ${ }^{1}$, YOUNG WAN KIM ${ }^{1}$, EUN HEE CHOI ${ }^{2}$ and IK YONG KIM ${ }^{1}$ \\ ${ }^{1}$ Department of Surgery, Division of Colorectal Surgery, and ${ }^{2}$ Institute of Lifestyle Medicine, \\ Yonsei University Wonju College of Medicine, Wonju, Republic of Korea
}

\begin{abstract}
Background: To evaluate factors associated with the lack of adjuvant chemotherapy after curative surgery in patients with stage II and III colon cancer based on national population-based data. Patients and Methods: A total of 8,412 patients diagnosed with stage II or III disease who underwent curative resection were included. Results: Adjuvant chemotherapy was not administered in 3,057 cases (36.34\%). Factors associated with the lack of chemotherapy were older age [hazard ratio $(H R)=1.50$ in patients $65-74$ years and 5.23 in patients $\geq 75$ years of age], female sex (HR=1.15), tumor-node-metastasis (TNM) stage II (HR=4.28), emergency surgery $(H R=1.45)$, American Society of Anesthesiologists (ASA) score of 3 or higher $(H R=1.62)$, fewer than 12 lymph nodes examined $(H R=1.19)$, a greater quantity of transfusion $(H R=1.08)$, and hospital type (tertiary referral center) $(H R=1.62)$. Conclusion: Patientrelated (older age, female sex, and ASA score of 3 or higher) and treatment-related factors (TNM stage II, emergency surgery, fewer than 12 lymph nodes examined, a greater quantity of transfusion, and hospital type) influenced the lack of adjuvant chemotherapy. Given that the use of adjuvant chemotherapy improves overall survival, physicians should make an effort to increase the proportion of patients receiving chemotherapy after surgery.
\end{abstract}

Complete surgical resection is the gold-standard treatment for localized colon cancer. After removal of the tumor, adjuvant chemotherapy is performed to destroy undetectable occult micrometastases, thereby minimizing the risk of recurrence

Correspondence to: Young Wan Kim, MD, Ph.D., Department of Surgery, Yonsei University Wonju College of Medicine, 20 Ilsanro, Wonju-si, Gangwon-do, 26426, Korea. Tel: +82 337410573, Fax: +82 337410574, e-mail: youngwkim@yonsei.ac.kr

Key Words: Colonic neoplasms, adjuvant chemotherapy, survival, mortality. and metastasis (1). Although it is difficult to estimate the survival benefits of adjuvant chemotherapy, chemotherapy with fluorouracil prolonged survival by $5 \%$ in patients with node-positive colon cancer in a meta-analysis (2). In stage III colon cancer, modern cytotoxic chemotherapy including oxaliplatin can reduce the risk of recurrence by approximately $30 \%$ or the risk of death by $22-32 \%$ (3).

The current National Comprehensive Cancer Network guidelines recommend adjuvant chemotherapy for stage II and III colon cancer following curative surgery (4); however, not all patients receive adjuvant chemotherapy. In the United States, only $67 \%$ of patients with stage III colon cancer received adjuvant chemotherapy after colectomy based on data from 2013 (5). The receipt of chemotherapy depends on the patient's age, ethnicity, comorbid disease, marital and socioeconomic status, and the presence of postoperative complications (6).

To date, the reasons for the lack of adjuvant chemotherapy have not been extensively investigated using a national population-based cohort study. Since 2011, the Korean Health Insurance Review and Assessment Service (HIRA, Seoul, Korea) has collected treatment data for all new patients with colon cancer to monitor the cancer treatment process and improve the quality of colon cancer care. Using the Korean population-based cohort, we investigated factors associated with the lack of adjuvant chemotherapy after curative surgery in patients with stage II and III colon cancer.

\section{Patients and Methods}

Patients. This was a retrospective study using national populationbased cohort data and was performed according to the Strengthening the Reporting of Observational Studies in Epidemiology (STROBE) guidelines (7). All clinical investigations were conducted following the principles expressed in the Declaration of Helsinki. This analysis was approved and participants' informed consent was waived by the Ethics Review Committee of the HIRA (Seoul, South Korea) and the Institutional Review Board of Wonju Severance Christian Hospital (YWMR-15-5-041). 
Table I. Details of hospital treatment data collected.

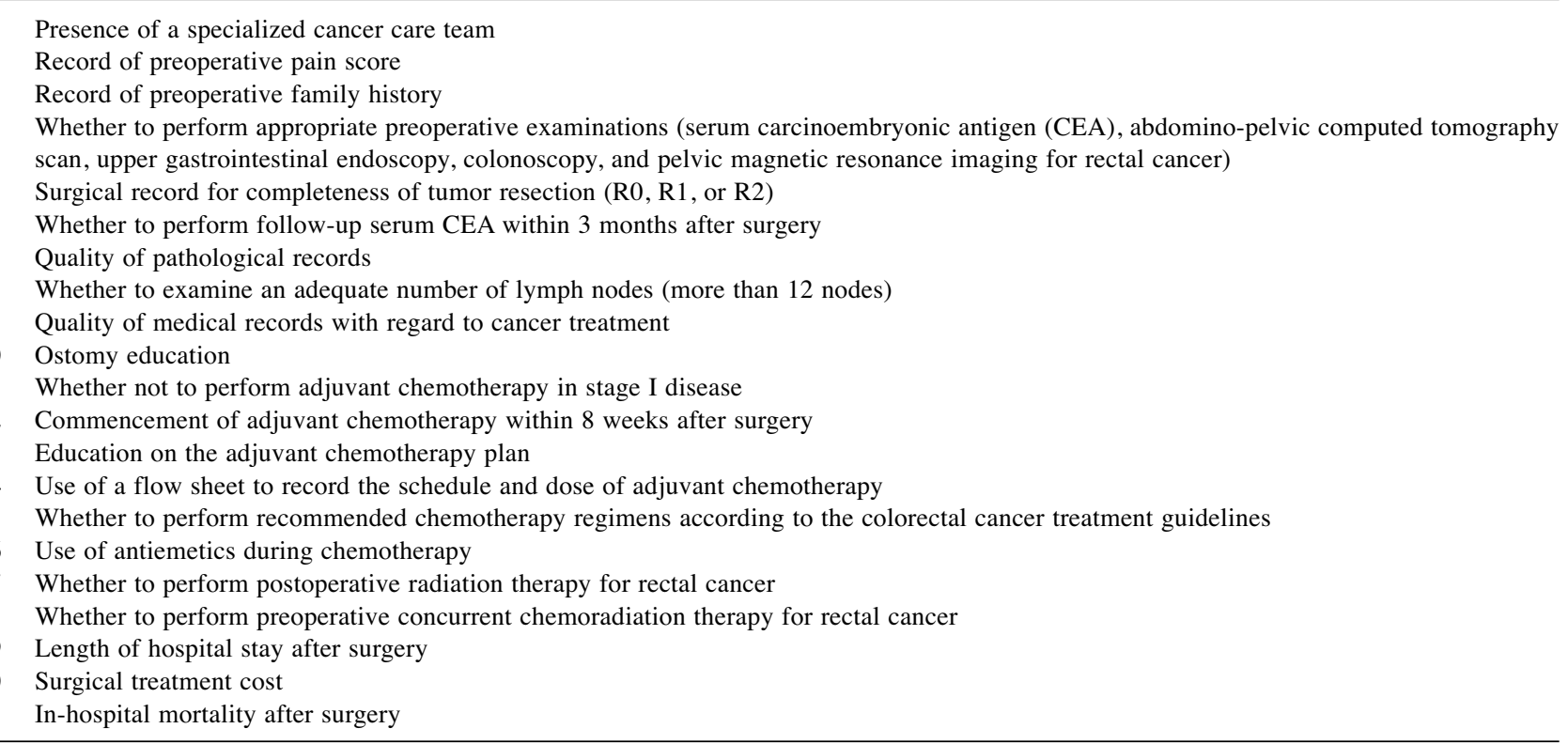

Between January 1, 2011 and December 31, 2012, a total of 8,412 patients with colon cancer who underwent curative resection and were diagnosed with stage II or III disease were included based on HIRA data obtained from all hospitals registered in the Korean HIRA. The inclusion criteria were histologically proven colonic adenocarcinoma and age older than 18 years. Exclusion criteria included stage I or IV disease, incomplete tumor removal (R2, macroscopic residual disease) or palliative non-resectional surgery, and rectal cancer.

Data source. In 2011, the Korean HIRA launched a project termed 'Monitoring and Evaluation of the Quality of Colon Cancer Care'. The HIRA collected hospital treatment data to improve the quality of colon cancer care at the national level. The diseases evaluated were colon and rectal adenocarcinoma, such as $\mathrm{C} 18$ (malignant neoplasm of the colon), C19 (malignant neoplasm of the rectosigmoid junction), and $\mathrm{C} 20$ (malignant neoplasm of the rectum), based on the International Statistical Classification of Diseases and Related Health Problems (ICD)-10 version (8). All hospitals in South Korea requesting reimbursement for colorectal cancer care have been mandated to submit 21 detailed items of treatment data on newly diagnosed patients older than 18 years of age. These 21 items submitted in detail are listed in Table I.

Study objective. The primary objective was to identify factors associated with the lack of adjuvant chemotherapy after curative surgery in patients with stage II and III colon cancer. The secondary objective was to evaluate the overall survival rates according to the use of adjuvant chemotherapy and prognostic factors for survival using Cox proportional hazard modeling.

Recommendation for adjuvant chemotherapy. The Korean government agency (HIRA) and the Korean Clinical Practice Guidelines for Colon and Rectal Cancer (v.1.0) recommend that all colon cancer patients with stage II or III disease receive adjuvant chemotherapy after curative resection $(9,10)$. The chemotherapeutic agents included fluoropyrimidine (fluorouracil with folinic acid, capecitabine) alone or in combination with oxaliplatin (FOLFOX). High-risk features for recurrences were defined when patients had T4 tumors, histological grade 3, peritumoral lymphovascular invasion, intestinal obstruction at presentation, T3 lesions with perforation or inadequate, indeterminate, or positive resection margins, or perineural invasion. In stage II disease, patients with high-risk features were recommended to receive a FOLFOX regimen.

Patients were followed-up until death or August 31, 2015. The date of death was collected from the National Health Insurance Service System (Seoul, Korea). The median follow-up period was 1,264 days (mean \pm standard deviation: 11,95.2 \pm 335.08 days).

Variables. In South Korea, the current National Health Insurance System covers all nationals, and the National Health Security System comprises two categories, health insurance and medical aid, based on economic status. The presence of comorbidity was defined when a patient had one of any medical condition presented in the Charlson comorbidity index (11). The quantity of blood transfusion was quantified as units received during the postoperative period in the hospital.

Statistical analysis. All statistical analyses were performed using MedCalc Statistical Software version 15.2.2 (MedCalc Software bvba, Ostend, Belgium) and SAS version 9.2 (SAS Institute Inc., Cary, NC, USA). Categorical variables are presented as frequencies and percentages and were analyzed by the chi-square test or Fisher's exact test as appropriate. Continuous variables are presented as the means and standard deviations and were analyzed by the twosample $t$-test.

Firstly, factors associated with the lack of chemotherapy were identified by univariable logistic regression analysis, and variables 
Table II. Factors associated with the lack of adjuvant chemotherapy in patients with stage II and III colon cancer $(n=8,412)$.

\begin{tabular}{|c|c|c|c|c|c|}
\hline \multirow[t]{2}{*}{ Variable } & \multicolumn{3}{|c|}{ Univariate analysis } & \multicolumn{2}{|c|}{ Multivariate analysis } \\
\hline & Chemotherapy $(\mathrm{N}=5,355)$ & No chemotherapy $(\mathrm{N}=3,057)$ & $p$-Value & OR $(95 \% \mathrm{CI})$ & $p$-Value \\
\hline \multicolumn{6}{|l|}{ Age (years) } \\
\hline Mean \pm SD & $62.90 \pm 11.13$ & $70.88 \pm 11.70$ & $<0.0001$ & NA & \\
\hline \multicolumn{6}{|l|}{ Age subgroups (years) } \\
\hline$<65$ & $2,804(52.36 \%)$ & $830(27.15 \%)$ & \multirow[t]{3}{*}{$<0.0001$} & 1 & \multirow[t]{3}{*}{$<0.0001$} \\
\hline $65-74$ & $1,749(32.66 \%)$ & $860(28.13 \%)$ & & $1.50(1.32-1.70)$ & \\
\hline$\geq 75$ & $802(14.98 \%)$ & $1,367(44.72 \%)$ & & $5.23(4.57-5.99)$ & \\
\hline \multicolumn{6}{|l|}{ Gender } \\
\hline Male & $3,187(59.51 \%)$ & $1,638(53.58 \%)$ & \multirow[t]{2}{*}{$<0.0001$} & 1 & \multirow[t]{2}{*}{0.0082} \\
\hline Female & $2168(40.49 \%)$ & $1,419(46.42 \%)$ & & $1.15(1.04-1.28)$ & \\
\hline \multicolumn{6}{|l|}{ Health security system } \\
\hline National health insurance & $5,024(93.82 \%)$ & $2,777(90.84 \%)$ & \multirow[t]{2}{*}{$<0.0001$} & 1 & \multirow[t]{2}{*}{0.067} \\
\hline Medical aid & $331(6.18 \%)$ & $280(9.16 \%)$ & & $1.20(0.99-1.47)$ & \\
\hline \multicolumn{6}{|l|}{ TNM } \\
\hline II & $2,022(37.76 \%)$ & $2,087(68.27 \%)$ & \multirow[t]{2}{*}{$<0.0001$} & $4.28(3.85-4.77)$ & \multirow[t]{2}{*}{$<0.0001$} \\
\hline III & $3,333(62.24 \%)$ & $970(31.73 \%)$ & & 1 & \\
\hline \multicolumn{6}{|l|}{ ASA score } \\
\hline 1,2 & $4,656(88.91 \%)$ & $2,250(75.76 \%)$ & \multirow[t]{2}{*}{$<0.0001$} & 1 & \multirow[t]{2}{*}{$<0.0001$} \\
\hline 3,4 & $581(11.09 \%)$ & $720(24.24 \%)$ & & $1.62(1.41-1.87)$ & \\
\hline \multicolumn{6}{|l|}{ Emergency } \\
\hline Yes & $355(6.64 \%)$ & $381(12.5 \%)$ & \multirow[t]{2}{*}{$<0.0001$} & $1.45(1.18-1.80)$ & \multirow[t]{2}{*}{0.0006} \\
\hline No & $4,993(93.36 \%)$ & $2,668(87.5 \%)$ & & 1 & \\
\hline \multicolumn{6}{|l|}{ Lymph nodes retrieved (number) } \\
\hline$<12$ & $491(9.41 \%)$ & $370(12.82 \%)$ & \multirow[t]{2}{*}{$<0.0001$} & $1.19(1.01-1.41)$ & \multirow[t]{2}{*}{0.0406} \\
\hline$\geq 12$ & $4,728(90.59 \%)$ & $2,515(87.18 \%)$ & & 1 & \\
\hline \multicolumn{6}{|l|}{ Comorbidity } \\
\hline+ & $3,902(72.87 \%)$ & $2,417(79.06 \%)$ & $<0.0001$ & $1.00(0.88-1.14)$ & 0.9787 \\
\hline \multicolumn{6}{|l|}{ Transfusion (units) } \\
\hline Mean \pm SD & $0.05 \pm 0.59$ & $0.31 \pm 4.35$ & 0.001 & $1.08(1.03-1.14)$ & 0.0033 \\
\hline \multicolumn{6}{|l|}{ Hospital type } \\
\hline Tertiary referral hospital & $4,952(92.47 \%)$ & $2,909(95.16 \%)$ & $<0.0001$ & $1.62(1.26-2.08)$ & 0.0002 \\
\hline General hospital ( $\geq 100$ beds) & $402(7.51 \%)$ & $148(4.84 \%)$ & & 1 & \\
\hline District hospital (<100 beds) & $1(0.02 \%)$ & $0(0 \%)$ & & NA & \\
\hline Chemotherapy regimen & & & & & \\
\hline Fluoropyrimidine-based & $2296(42.88 \%)$ & $0(\%)$ & - & NA & \\
\hline Oxaliplatin-based & $3,059(57.12 \%)$ & $0(\%)$ & & & \\
\hline
\end{tabular}

OR, Odds ratio; CI, confidence interval; NA, not applicable; SD, standard deviation; TNM, tumor-node-metastasis; ASA, American Society of Anesthesiologists.

with a $p$-value of less than 0.05 were utilized for multivariate analysis. Multivariate logistic regression analysis was then performed by the forward stepwise selection of variables. Survival and prognostic factor analyses were performed by the Kaplan-Meier method with log-rank tests and the Cox proportional hazards model. A $p$-value of less than 0.05 was considered statistically significant.

\section{Results}

Factors associated with the lack of adjuvant chemotherapy. Among 8,412 patients with stage II $(n=4,109)$ or III $(\mathrm{n}=4,303)$ disease, adjuvant chemotherapy was not administered in 3,057 cases (36.34\%). Among 5,355 patients with adjuvant chemotherapy, the chemotherapy agents included fluoropyrimidine $(\mathrm{n}=2,296,42.88 \%)$ and oxaliplatin $(\mathrm{n}=3,059,57.12 \%)$.

Based on the multivariate analysis, the factors associated with the lack of chemotherapy were older age [hazard ratio $(H R)=1.50$ in patients $65-74$ years and 5.23 in patients $\geq 75$ years of age, $p<0.0001]$, female sex $(\mathrm{HR}=1.15, p=0.0082)$, tumor-node-metastasis (TNM) stage II $(\mathrm{HR}=4.28$, $p<0.0001$ ), American Society of Anesthesiologists (ASA) score of 3 or higher $(\mathrm{HR}=1.62, p<0.0001)$, emergency surgery $(\mathrm{HR}=1.45, p=0.0006)$, fewer than 12 lymph nodes examined $(\mathrm{HR}=1.19, p=0.0406)$, a greater quantity of transfusion $(\mathrm{HR}=1.08, p=0.0033)$, and hospital type (tertiary referral center $)(\mathrm{HR}=1.62, p=0.0002)$ (Table II). 
Table III. Overall survival rates in patients with stage II and III colon cancer according to the receipt of adjuvant chemotherapy (N=8,412).

\begin{tabular}{lcccccc}
\hline Chemotherapy & Parameter & Baseline & 1-Year & 2-Year & 3-Year & 4-Value \\
\hline \multirow{2}{*}{ Yes } & Number at risk & 5,355 & 5,235 & 5,012 & 4,208 \\
& Proportion surviving & $100 \%$ & $97.76 \%$ & $93.59 \%$ & $89.37 \%$ \\
No & Number at risk & 3,057 & 2,683 & 2,469 & $85.64 \%$ \\
& Proportion surviving & $100 \%$ & $87.77 \%$ & $80.77 \%$ & $75.52 \%$ \\
\hline
\end{tabular}

*By log-rank test.

Overall survival rates according to the use of adjuvant chemotherapy. The 1-year overall survival rates were $97.76 \%$ and $87.77 \%$ in the chemotherapy and no chemotherapy groups, respectively. The 3-year overall survival rates were $89.37 \%$ and $75.52 \%$ in the chemotherapy and no chemotherapy groups, respectively $(p<0.001)$ (Figure 1 , Table III).

Prognostic factors for survival using Cox proportional hazard modeling. Adverse prognostic factors for overall survival included the lack of adjuvant chemotherapy $(\mathrm{HR}=1.93, p<0.0001)$, older age $(\mathrm{HR}=1.83$ in patients $65-74$ years and 3.08 in patients $\geq 75$ years of age, $p<0.0001)$, TNM stage III $(\mathrm{HR}=2.45, p<0.0001)$, ASA score of 3 or higher $(\mathrm{HR}=1.79, p<0.0001)$, emergency surgery $\quad(\mathrm{HR}=2.36$, $p<0.0001)$, fewer lymph nodes examined $(\mathrm{HR}=1.43$, $p<0.0001)$, and a greater quantity of transfusion $(\mathrm{HR}=1.03$, $p<0.0001$ ) (Table IV).

\section{Discussion}

This study shows that a significant proportion $(36.34 \%)$ of patients with stage II and III disease do not receive adjuvant chemotherapy after curative surgery. In population-based studies, rates of adjuvant chemotherapy ranged from $41 \%$ to 93.9\% (Table V) (12-28). The major finding of this study is that factors affecting the lack of chemotherapy were older age, female sex, TNM stage II, emergency surgery, ASA score of 3 or higher, fewer than 12 lymph nodes examined, a greater quantity of transfusion, and hospital type (tertiary referral center). Survival analysis confirmed that the lack of chemotherapy was associated with unfavorable overall survival, which indicates that increased administration of adjuvant chemotherapy could improve the outcomes of colon cancer care.

Diverse factors are associated with no receipt of adjuvant chemotherapy. Older age is a well-known risk factor for the lack of adjuvant chemotherapy (12-16, 18-26, 28). We also observed that the lack of chemotherapy was associated with increasing age based on age subgroup analysis. Chronological aging is related to diminished physiological

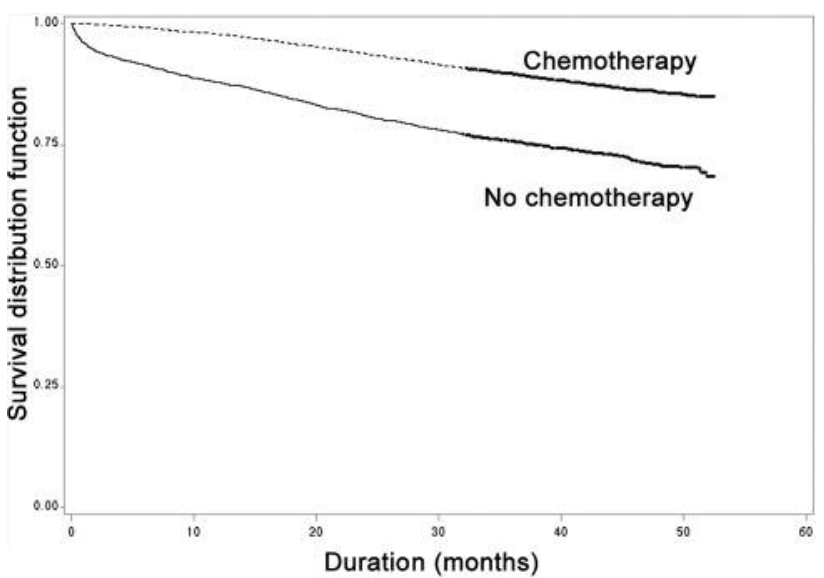

Figure 1. Overall survival rates in patients with stage II and III colon cancer according to the receipt of adjuvant chemotherapy $(N=8,412)$.

reserve and high susceptibility to comorbidities. Thus, with elderly patients, the patient, physician, or both tend to be discouraged from using adjuvant chemotherapy (15, 29). Four population-based studies focusing on elderly patients aged 65-79 years (14), 66-99 years (15), or over 65 years $(19,21)$ showed rates of chemotherapy that ranged from $41 \%$ to $63 \%$. In this series, $53.4 \%$ of patients aged 65 years or older received chemotherapy.

Female sex has been reported as a significant factor for the lack of adjuvant chemotherapy $(14,16,23,24,28)$, as reported in the current study. However, in a study by Lin et al. (25), male sex was a risk factor for the lack of chemotherapy. The underlying mechanism in the role of sex has not been elucidated; however, Oliver et al. suggested that in female patients, fragile condition or poor economic status may preclude physicians' willingness to perform chemotherapy (23).

In this study, TNM stage II was associated with a lack of chemotherapy. In the literature, advanced tumor stage, in terms of a greater number of positive lymph nodes $(12,15$, $21,24,25)$ or TNM III stage (23) compared to TNM II stage, has been associated with the more frequent use of adjuvant 
Table IV. Prognostic factors for overall survival in patients with stage II and III colon cancer $(n=8,412)$.

\begin{tabular}{|c|c|c|c|c|}
\hline \multirow[t]{2}{*}{ Variable } & \multicolumn{3}{|c|}{ Univariate analysis } & \multirow{2}{*}{$\begin{array}{c}\text { Multivariate analysis } \\
\text { p-Value }\end{array}$} \\
\hline & HR $(95 \% \mathrm{CI})$ & $p$-Value & HR $(95 \% \mathrm{CI})$ & \\
\hline \multicolumn{5}{|l|}{ Adjuvant chemotherapy } \\
\hline Yes & 1 & \multirow[t]{2}{*}{$<0.0001$} & 1 & \multirow[t]{2}{*}{$<0.0001$} \\
\hline No & $2.4(2.17-2.66)$ & & $1.93(1.71-2.18)$ & \\
\hline \multicolumn{5}{|l|}{ Age subgroups (years) } \\
\hline$<65$ & 1 & \multirow[t]{3}{*}{$<0.0001$} & 1 & \multirow[t]{3}{*}{$<0.0001$} \\
\hline $65-74$ & $2.01(1.74-2.32)$ & & $1.83(1.57-2.13)$ & \\
\hline$\geq 75$ & $4.66(4.09-5.30)$ & & $3.08(2.65-3.58)$ & \\
\hline \multicolumn{5}{|l|}{ Gender } \\
\hline Male & $1.01(0.91-1.12)$ & \multirow[t]{2}{*}{0.8261} & \multirow[t]{2}{*}{ NA } & \\
\hline Female & 1 & & & \\
\hline \multicolumn{5}{|l|}{ Health security system } \\
\hline National health insurance & 1 & \multirow[t]{2}{*}{$<0.0001$} & 1 & \multirow[t]{2}{*}{0.1405} \\
\hline Medical aid & $1.64(1.40-1.93)$ & & $1.15(0.96-1.37)$ & \\
\hline \multicolumn{5}{|l|}{ TNM } \\
\hline II & 1 & \multirow[t]{2}{*}{$<0.0001$} & 1 & \multirow[t]{2}{*}{$<0.0001$} \\
\hline III & $1.84(1.66-2.05)$ & & $2.45(2.18-2.75)$ & \\
\hline \multicolumn{5}{|l|}{ Emergency } \\
\hline Yes & $3.42(3.02-3.88)$ & \multirow[t]{2}{*}{$<0.0001$} & $2.36(2.02-2.74)$ & \multirow[t]{2}{*}{$<0.0001$} \\
\hline No & 1 & & 1 & \\
\hline \multicolumn{5}{|l|}{ ASA score } \\
\hline 1,2 & 1 & \multirow[t]{2}{*}{$<0.0001$} & 1 & \multirow[t]{2}{*}{$<0.0001$} \\
\hline 3,4 & $2.98(2.68-3.33)$ & & $1.79(1.58-2.03)$ & \\
\hline \multicolumn{5}{|c|}{ Lymph nodes retrieved (number) } \\
\hline$<12$ & $1.77(1.54-2.04)$ & \multirow[t]{2}{*}{$<0.0001$} & $1.43(1.24-1.66)$ & \multirow[t]{2}{*}{$<0.0001$} \\
\hline$\geq 12$ & 1 & & 1 & \\
\hline \multicolumn{5}{|l|}{ Comorbidity } \\
\hline$+v s .-$ & $1.28(1.13-1.45)$ & 0.0001 & $0.98(0.86-1.12)$ & 0.7795 \\
\hline Transfusion (units) & $1.03(1.03-1.04)$ & $<0.0001$ & $1.03(1.02-1.04)$ & $<0.0001$ \\
\hline
\end{tabular}

HR, Hazard ratio; CI, confidence interval; NA, not applicable; TNM, tumor-node-metastasis; ASA, American Society of Anesthesiologists.

chemotherapy. This finding might be explained by the need for increased oncological consultation (15) or physicians' recommendation for more aggressive treatment for more advanced tumors.

In this study, an ASA score of 3 or higher was associated with a lack of chemotherapy. The ASA score is a sixcategory physical status classification system reflecting preoperative functional status, and patients with an ASA score of 1 (healthy), 2 (mild systemic), or 3 (severe systemic disease) are candidates for elective colon cancer resection. The functional status of patients with cancer is important before considering the use of chemotherapy, and the Eastern Cooperative Oncology Group score or Karnofsky score are also used to determine a patient's performance status. However, few studies have focused on the relation between functional status and the receipt of adjuvant chemotherapy $(22,29)$. Another study showed that poor performance status was associated with the underuse of palliative chemotherapy in patients with stage IV disease (10). The patient's functional status is also influenced by comorbidity, which is related to the receipt of chemotherapy $(12-18,20,21,23,25$, 26, 28). A greater Charlson comorbidity score has been associated with a lower rate of chemotherapy use (12-16, 18, $20,21,23,25,26,28)$, and Gross et al. (17) observed that the presence of congestive heart failure, chronic obstructive pulmonary disease, or diabetes was associated with the lack of adjuvant chemotherapy. Unlike the ASA score, comorbidity was not a significant predictor for chemotherapy use in our study.

Complicated postoperative recovery in terms of severe surgical complications (22), reoperation (22, 24), or prolonged hospital stay $(13,24)$ has been shown to increase the lack of chemotherapy. Although we were unable to obtain data regarding postoperative complications in this study, emergency surgery, fewer than 12 lymph nodes examined, and a greater quantity of transfusion were associated with the lack of chemotherapy. We speculate that these factors are surgical treatment-related. Indeed, emergency surgery is more likely to cause postoperative complications (30) or low lymph node yield (31), and 
Table V. Population-based cohort studies regarding the administration of adjuvant chemotherapy for colon cancer.

\begin{tabular}{|c|c|c|c|c|c|c|}
\hline Author (Ref) & Year & Data source & $\mathrm{N}$ & $\begin{array}{c}\text { Chemotherapy } \\
\text { receipt }(\%)\end{array}$ & Stage & Significant factors \\
\hline Schrag et al. (12) & 2001 & SEER & 6,262 & $55 \%$ & III & $\begin{array}{l}\text { Age, race, no. of positive lymph nodes, } \\
\text { comorbidity, year of diagnosis }\end{array}$ \\
\hline Baldwin et al. (13) & 2005 & SEER & 5,294 & $59.8 \%$ & III & $\begin{array}{c}\text { Age, race, comorbidity, married, surgical length of stay, } \\
\text { rehospitalization, region }\end{array}$ \\
\hline Lemmens et al. (14) & 2005 & Netherlands & $577 *$ & $41 \%$ & III & Sex, socioeconomic status, comorbidity, year of diagnosis \\
\hline Luo et al. (15) & 2006 & SEER & $7,569 *$ & $58.5 \%$ & III & $\begin{array}{c}\text { Age, race, marital status, year of diagnosis, no. of } \\
\text { positive lymph nodes, comorbidity }\end{array}$ \\
\hline McGory et al. (16) & 2006 & $\mathrm{CA}$ & 13,231 & $48 \%$ & III & $\begin{array}{c}\text { Age, sex, race, insurance, comorbidity, poverty, } \\
\text { college education }\end{array}$ \\
\hline Gross et al. (17) & 2007 & SEER & 5,330 & $60.3 \%$ & III & Comorbidities (CHF, COPD, diabetes) \\
\hline Cress et al. (18) & 2009 & SEER & 973 & $67 \%$ & III & $\begin{array}{l}\text { Residence (state, education level, non-working class } \\
\text { neighborhood), age, comorbidity, marital status }\end{array}$ \\
\hline Davidoff et al. (19) & 2009 & SEER & $7,176^{*}$ & $51.7 \%$ & III & Race \\
\hline Winget et al. (20) & 2010 & Canada & 618 & $63 \%$ & III & Age, comorbidity \\
\hline Hsieh et al. (21) & 2013 & SEER & $13,608 *$ & $56 \%$ & III & $\begin{array}{l}\text { Age, race, socioeconomic status, marital status, } \\
\text { intestinal obstruction, no. of positive lymph nodes, } \\
\text { comorbidity, diagnosis year }\end{array}$ \\
\hline Merkow et al. (22) & 2013 & ACS-NSQIP & 2,368 & $63.2 \%$ & III & $\begin{array}{l}\text { Age, ASA, functional status, body mass index, income, } \\
\text { serious complication, organ space SSI, prolonged ventilation, } \\
\text { reintubation, pneumonia, VTE, renal failure, } \\
\text { sepsis/shock, return to operating room }\end{array}$ \\
\hline Oliver et al. (23) & 2013 & $\mathrm{AL}$ & 1,182 & $93.9 \%$ & II \& III & Age, sex, stage III, comorbidity \\
\hline van der Geest et al. (24) & 2013 & Netherlands & 606 & $60 \%$ & III & $\begin{array}{l}\text { Age, sex, tumor stage, reoperation, prolonged } \\
\text { postoperative hospital stay }\end{array}$ \\
\hline Lin et al. (25) & 2015 & $\mathrm{NCDB}$ & 34,694 & $75.7 \%$ & III & $\begin{array}{c}\text { Age, sex, travel distance, race, insurance, facility type, } \\
\text { comorbidity, no. of positive lymph nodes, tumor grade, } \\
\text { region (univariate) }\end{array}$ \\
\hline Murphy et al. (26) & 2015 & SEER & 1,849 & $65.4 \%$ & III & Age, race/ethnicity, comorbidity, year of diagnosis \\
\hline Murphy et al. (27) & 2015 & SEER & 1,219 & $64.6 \%$ & III & Race/ethnicity \\
\hline Upadhyay et al. (28) & 2015 & $\mathrm{NCDB}$ & 207,718 & $62 \%$ & III & $\begin{array}{c}\text { Age, sex, race/ethnicity, treatment facility, year of } \\
\text { treatment, insurance, education, income, comorbidity, } \\
\text { distance to facility (univariate) }\end{array}$ \\
\hline Current study & 2016 & Korean HIRA & 8,412 & $63.7 \%$ & II \& III & $\begin{array}{l}\text { Age, sex, TNM stage, ASA, emergency surgery, } \\
\text { lymph nodes examined, transfusion, hospital type }\end{array}$ \\
\hline
\end{tabular}

SEER, Surveillance Epidemiology and End Results-Medicare; CA, California Cancer Registry, California Discharge Records, 2000 census; CHF, congestive heart failure; COPD, chronic obstructive pulmonary disease; ACS-NSQIP, American College of Surgeons National Surgical Quality Improvement Program; SSI, surgical site infection; VTE, venous thromboembolism; AL, Alabama; NCDB, National Cancer Data Base; HIRA, Health Insurance Review and Assessment Service; TNM, tumor-node-metastasis; ASA, American Society of Anesthesiologists. *Elderly patients only.

complicated postoperative recovery is linked to a greater quantity of transfusion (32).

In this study, treatment in a tertiary referral center was associated with a lack of chemotherapy. This finding might be due to the rather small study sample of the general hospital group compared to those of the tertiary center and that patients with more severe conditions are more likely to be treated in a tertiary center. In contrast to our results, an academic center (28) and the facility of the National Cancer Institute program (25) showed increased rates of chemotherapy among patients at a tertiary referral center.

In the literature, other factors such as race/ethnicity $(12,13$, $15,16,19,21,25-28)$, marital status $(13,15,18,21)$, residence
$(13,18,25,28)$, education $(16,28)$, insurance $(16,25,28)$ and year of diagnosis $(12,14,15,21,26,28)$ have been reported to be significant risk factors for the lack of chemotherapy.

This study was limited by its retrospective design. In addition, data on short-term surgical outcomes, such as postoperative complications and severity, and data for stage II disease in high-risk patients, were not available. However, this study has some strengths. The study cohort included a significant quantity of Korean population data and was based on highly credible data collected by a government health service agency. The study was also performed in a recent period and with current chemotherapeutic agents based on the current chemotherapy guidelines for colon cancer. 
In summary, patient-related (older age, female, and ASA score of 3 or higher) and treatment-related factors (TNM stage II, emergency surgery, fewer than 12 lymph nodes examined, a greater quantity of transfusion, and hospital type) influenced the lack of adjuvant chemotherapy based on this national population-based cohort study. Given that the use of adjuvant chemotherapy improves overall survival, physicians should make efforts to increase the proportion of patients receiving chemotherapy after surgery.

\section{Conflicts of Interest}

Each Author confirms that they have no commercial associations that might pose a conflict of interest in connection with this article.

\section{Competing Interests}

The Authors have no competing interests to declare.

\section{Acknowledgements}

The Authors thank Dr. Bo Ra Kim for performing miscellaneous data analysis, without which this study would not have been possible.

\section{References}

1 Andre T, Boni C, Navarro M, Tabernero J, Hickish T, Topham C, Bonetti A, Clingan P, Bridgewater J, Rivera $\mathrm{F}$ and de Gramont A: Improved overall survival with oxaliplatin, fluorouracil, and leucovorin as adjuvant treatment in stage II or III colon cancer in the MOSAIC trial. J Clin Oncol 27(19): 3109-3116, 2009.

2 Dube S, Heyen F and Jenicek M: Adjuvant chemotherapy in colorectal carcinoma: results of a meta-analysis. Dis Colon Rectum 40(1): 35-41, 1997.

3 Clark JW and Sanoff HK: Adjuvant therapy for resected stage III (node-positive) colon cancer. In: UpToDate (Post T, ed). UpToDate, Waltham, MA, USA (Accessed on November 10, 2016).

4 National Comprehensive Cancer Network. National comprehensive cancer network guidelines, Colon cancer (Version 2.2016). http://www.nccn.org/professionals/physician_ gls/pdf/colon.pdf. Accessed September 1, 2016.

5 Miller KD, Siegel RL, Lin CC, Mariotto AB, Kramer JL, Rowland JH, Stein KD, Alteri R and Jemal A: Cancer treatment and survivorship statistics, 2016. CA Cancer J Clin 66(4): 271289, 2016.

6 Etzioni DA, El-Khoueiry AB and Beart RW Jr.: Rates and predictors of chemotherapy use for stage III colon cancer: a systematic review. Cancer 113(12): 3279-3289, 2008.

7 von Elm E, Altman DG, Egger M, Pocock SJ, Gotzsche PC and Vandenbroucke JP: The Strengthening the Reporting of Observational Studies in Epidemiology (STROBE) statement: guidelines for reporting observational studies. Lancet 370(9596): 1453-1457, 2007

8 Kim JH, Son KY, Shin DW, Kim SH, Yun JW, Shin JH, Kang MS, Chung EH, Yoo KH and Yun JM: Network analysis of human diseases using Korean nationwide claims data. J Biomed Inform 61: 276-282, 2016.

9 Korean Academy of Medical Science: Korean clinical practice guideline for colon and rectal cancer v.1.0. Seoul, Korean Academy of Medical Science. 2012.

$10 \mathrm{Kim}$ YW and Kim IY: The role of surgery for asymptomatic primary tumors in unresectable stage IV colorectal cancer. Ann Coloproctol 29(2): 44-54, 2013.

11 Charlson ME, Pompei P, Ales KL and MacKenzie CR: A new method of classifying prognostic comorbidity in longitudinal studies: development and validation. J Chronic Dis 40(5): 373383, 1987.

12 Schrag D, Cramer LD, Bach PB and Begg CB: Age and adjuvant chemotherapy use after surgery for stage III colon cancer. J Natl Cancer Inst 93(11): 850-857, 2001.

13 Baldwin LM, Dobie SA, Billingsley K, Cai Y, Wright GE, Dominitz JA, Barlow W, Warren JL and Taplin SH: Explaining Black-White differences in receipt of recommended colon cancer treatment. J Natl Cancer Inst 97(16): 1211-1220, 2005.

14 Lemmens VE, van Halteren AH, Janssen-Heijnen ML, Vreugdenhil G, Repelaer van Driel OJ and Coebergh JW: Adjuvant treatment for elderly patients with stage III colon cancer in the southern Netherlands is affected by socioeconomic status, gender, and comorbidity. Ann Oncol 16(5): 767-772, 2005.

15 Luo R, Giordano SH, Freeman JL, Zhang D and Goodwin JS: Referral to medical oncology: a crucial step in the treatment of older patients with stage III colon cancer. Oncologist 11(9): 1025-1033, 2006.

16 McGory ML, Zingmond DS, Sekeris E, Bastani R and Ko CY: A patient's race/ethnicity does not explain the underuse of appropriate adjuvant therapy in colorectal cancer. Dis Colon Rectum 49(3): 319-329, 2006.

17 Gross CP, McAvay GJ, Guo Z and Tinetti ME: The impact of chronic illnesses on the use and effectiveness of adjuvant chemotherapy for colon cancer. Cancer 109(12): 2410-2419, 2007.

18 Cress RD, Sabatino SA, Wu XC, Schymura MJ, Rycroft R, Stuckart E, Fulton $\mathrm{J}$ and Shen T: Adjuvant chemotherapy for patients with stage III colon cancer: Results from a CDC-NPCR patterns of care study. Clin Med Oncol 3: 107-119, 2009.

19 Davidoff AJ, Rapp T, Onukwugha E, Zuckerman IH, Hanna N, Pandya $\mathrm{N}$ and Mullins CD: Trends in disparities in receipt of adjuvant therapy for elderly stage III colon cancer patients: the role of the medical oncologist evaluation. Med Care 47(12): 1229-1236, 2009.

20 Winget M, Hossain S, Yasui Y and Scarfe A: Characteristics of patients with stage III colon adenocarcinoma who fail to receive guideline-recommended treatment. Cancer 116(20): 4849-4856, 2010.

21 Hsieh MC, Chiu YW, Velasco C, Wu XC, O'Flarity MB and Chen VW: Impact of race/ethnicity and socioeconomic status on adjuvant chemotherapy use among elderly patients with stage III colon cancer. J Registry Manag 40(4): 180-187, 2013.

22 Merkow RP, Bentrem DJ, Mulcahy MF, Chung JW, Abbott DE, Kmiecik TE, Stewart AK, Winchester DP, Ko CY and Bilimoria KY: Effect of postoperative complications on adjuvant chemotherapy use for stage III colon cancer. Ann Surg 258(6): 847-853, 2013.

23 Oliver JS, Martin MY, Richardson L, Kim Y and Pisu M: Gender differences in colon cancer treatment. J Womens Health 22(4): 344-351, 2013. 
24 van der Geest LG, Portielje JE, Wouters MW, Weijl NI, Tanis BC, Tollenaar RA, Struikmans H and Nortier JW: Complicated postoperative recovery increases omission, delay and discontinuation of adjuvant chemotherapy in patients with Stage III colon cancer. Colorectal Dis 15(10): e582-591, 2013.

25 Lin CC, Bruinooge SS, Kirkwood MK, Olsen C, Jemal A, Bajorin D, Giordano SH, Goldstein M, Guadagnolo BA, Kosty M, Hopkins S, Yu JB, Arnone A, Hanley A, Stevens S and Hershman DL: Association between geographic access to cancer care, insurance, and receipt of chemotherapy: geographic distribution of oncologists and travel distance. J Clin Oncol 33(28): 3177-3185, 2015.

26 Murphy CC, Harlan LC, Lund JL, Lynch CF and Geiger AM: Patterns of colorectal cancer care in the United States: 19902010. J Natl Cancer Inst 107(10): djv198, 2015.

27 Murphy CC, Harlan LC, Warren JL and Geiger AM: Race and insurance differences in the receipt of adjuvant chemotherapy among patients with stage III colon cancer. J Clin Oncol 33(23): 2530-2536, 2015.

28 Upadhyay S, Dahal S, Bhatt VR, Khanal N and Silberstein PT: Chemotherapy use in stage III colon cancer: a National Cancer Database analysis. Ther Adv Med Oncol 7(5): 244-251, 2015.
29 Kim IY, Kim BR and Kim YW: Factors affecting use and delay $(>/=8$ weeks $)$ of adjuvant chemotherapy after colorectal cancer surgery and the impact of chemotherapy-use and delay on oncologic outcomes. PLoS One 10(9): e0138720, 2015.

$30 \mathrm{Kim}$ IY, Kim BR and Kim YW: Outcomes of laparoscopic and open surgery for colorectal cancer in the emergency setting. In Vivo 29(2): 295-300, 2015

$31 \mathrm{Kim}$ YW, Kim NK, Min BS, Lee KY, Sohn SK and Cho CH: The influence of the number of retrieved lymph nodes on staging and survival in patients with stage II and III rectal cancer undergoing tumor-specific mesorectal excision. Ann Surg 249(6): 965-972, 2009.

32 Kim IY, Kim BR, Kim HS and Kim YW: Differences in clinical features between laparoscopy and open resection for primary tumor in patients with stage IV colorectal cancer. Onco Targets Ther 8: 3441-3448, 2015.

Received December 13, 2016

Revised January 25, 2017

Accepted January 27, 2017 